\title{
Seismic Behavior of RC Moment Resisting Structures with Concrete Shear Wall under Mainshock-aftershock Seismic Sequences
}

Omid Karimzade Soureshjani

Kharazmi University

Ali Massumi ( $\nabla$ ali.massumi@gmail.com )

Kharazmi University https://orcid.org/0000-0003-4636-6553

\section{Research Article}

Keywords: mainshock-aftershock, seismic sequences, shear wall, RC structures, seismic behavior, nonlinear behavior, ratio of aftershock to mainshock acceleration

Posted Date: July 28th, 2021

DOI: https://doi.org/10.21203/rs.3.rs-739616/v1

License: (c) (i) This work is licensed under a Creative Commons Attribution 4.0 International License. Read Full License

Version of Record: A version of this preprint was published at Bulletin of Earthquake Engineering on January 7th, 2022. See the published version at https://doi.org/10.1007/s10518-021-01291-x. 


\title{
Seismic behavior of $\mathrm{RC}$ moment resisting structures with concrete shear wall under mainshock-aftershock seismic sequences
}

\author{
Omid Karimzade Soureshjani, Ph.D. Candidate of Structural Engineering, Kharazmi University \\ Postal address: Kharazmi University, No.43, Dr. Mofatteh Ave., Tehran, IRAN \\ ORCID iD: https://orcid.org/0000-0003-4310-0194
}

Ali Massumi, Professor of Structural Engineering, Kharazmi University

Postal address: Kharazmi University, No.43, Dr. Mofatteh Ave., Tehran, IRAN

ORCID iD: https://orcid.org/0000-0003-4636-6553

Corresponding author: Ali Massumi

Email address: massumi@khu.ac.ir

Telephone: +982188830891

\begin{abstract}
A structure may subject to several aftershocks after a mainshock. In many seismic design provisions, the effect of the seismic sequences is not directly considered or underestimated. This paper studies the seismic behavior of RC moment-resisting structures with concrete shear wall under seismic sequences. Two three-dimensional structures of short and medium height were designed and analyzed. The former models were studied under a group of real mainshock-aftershock seismic sequences. The models were loaded and designed according to the fourth edition of the Iranian seismic code of standard no. 2800 and ACI-318 respectively. Furthermore, the non-linear dynamic time-history finite element analysis of models was performed via the explicit method. The parameters of maximum displacement, inter-story drift ratio, residual displacement, and finally the effect of the ratio of aftershock acceleration to mainshock acceleration were investigated and assessed. Due to the high lateral stiffness of shear walls, parallel with the complete elastic behavior, aftershocks cause no growth in inter-story drift ratio and relative displacement in the short structure model. In contrast, compared to the structure under the solely mainshock, the medium height structure model under seismic sequences showed significant growth in the amount of relative displacement (even more than 50\% growth), inter-story drift ratio, plastic strain, and residual displacement (almost 30\% growth). Furthermore, unlike the moment-resisting frame structures, models showed no significant growth in the drift ratio with the height. Assessments indicated that the ratio of aftershock to mainshock acceleration is a determinative parameter in structural behavior under seismic sequences.
\end{abstract}

Keywords: mainshock-aftershock, seismic sequences, shear wall, RC structures, seismic behavior, nonlinear behavior, ratio of aftershock to mainshock acceleration

\section{Introduction}

An earthquake in seismic zones is not a single event and in most cases a chain of ground motions with different magnitudes accompanies it. Multiple earthquakes occur around the world, especially in regions with complex fault systems. These fault systems usually do not release all the accumulated strain energy during the first vibration or mainshock; Thus, 
tensions and strains are formed in different locations of the fault system and lead to consecutive vibrations or aftershocks. This procedure continues until the fault system stabilizes thoroughly (Ōmori, 1984). The aftershocks have distractive effects on the dynamic behavior of the structures in terms of plastic strain, residual displacement, and so on. Previous studies show that the repair of structures damaged by mainshock and aftershocks, in most cases leads to failure, mainly due to short time intervals between the mainshock and aftershocks. In this regard, most of the structural damages originate from the significant reduction in stiffness and strength of structural members and the failure of materials due to repetitive seismic loading (Dulinska \& Murzyn, 2016). As mentioned, structures that are located in seismic zones are not encountered only with a single shock but also affected by a series of seismic sequences, such as mainshock and aftershocks. However, a structure that resists the mainshock may destroy during the aftershocks (Amadio et al., 2003). In some cases, due to strength and stiffness degradation due to seismic cycle loading, aftershocks cause more lateral displacements (even more than twice) compared to the mainshock which indicates aftershocks can be destructive for structures (Hosseini et al., 2019; Tarigan et al., 2018). Michoacán earthquake (Mexico City, 1985) with respectively the mainshock and aftershock of 8 and 6.6 Richter and Northridge earthquake (Los Angeles, 1994) with a magnitude of 6.7 Richter followed by a 6 Richter aftershock are good examples of this complicated event (Amadio et al., 2003). Despite their devastative structural effect, in most of the analytical studies and design codes, the effect of aftershocks has been neglected, underestimated, or has not been considered directly.

Due to less relative displacement, more energy absorption, and reliable seismic behavior, in comparison to some other structural systems, the seismic design of RC moment-resisting buildings with shear wall systems has attracted a lot of attention (Astaneh-Asl, 2002; Qu \& Bruneau, 2009). In this regard, Fig. 1 illustrates a comparison between a typical RC building and an RC building with a shear wall system. Shear walls are vertical elements that resist lateral or horizontal loads. In the medium to tall buildings, the shear wall system is usually used to decrease the effect of earthquake loads, as well as handling gravitational loads. Shear walls behave like a deep cantilever beam which provides lateral stability and stiffness for structure. Furthermore, the shear wall system can be used for short specially designed structures (Mostofinejad, 2008). Shear walls are designed in such a way to behave ductile under dynamic loading and chiefly under seismic loads (Wallace, 1994). This kind of structural system should be able to tolerate earthquake loads without falling and any major damage. Shear walls usually endure a high value of structural shear forces (whole or large amount). The best case is that during a vigorous earthquake, a shear wall exhibits a complete elastic behavior. However, building such a shear wall is not an economic or practical structure system. Indeed, the shear wall has to exhibit ductile behavior (Astaneh-Asl, 2002).

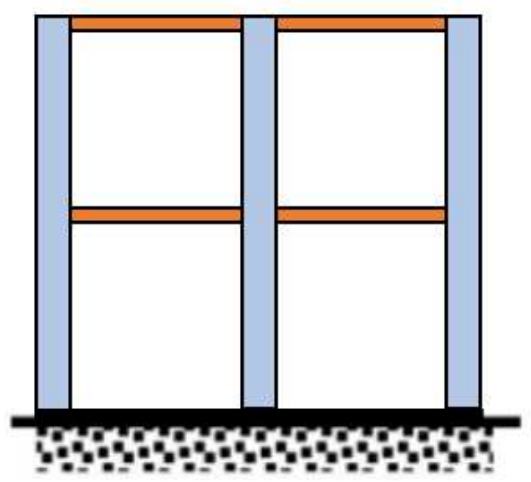

RC frame building

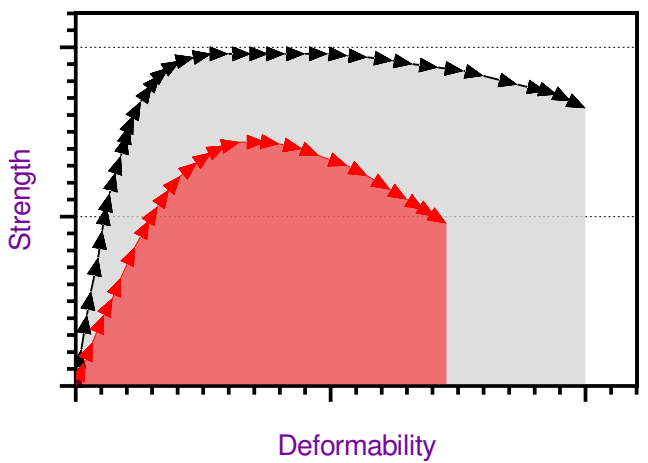

Deformability

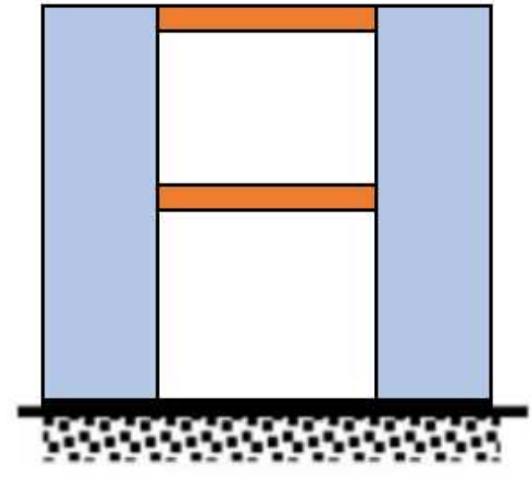

RC shear wall building

Fig. 1. Comparison between RC moment-resisting frame building and RC shear wall building

Considering the structural destruction during Nicaragua (1972), Mexico (1985), and Armenia (1988) earthquakes, the application of shear walls especially in seismic areas, is vital (Astaneh-As1, 2002; Qu \& Bruneau, 2009; Mostofinejad, 2008; Wallace, 1994).

The effect of aftershocks on three 2-dimensional (2D) steel frames was studied (Ruiz-García \& Negrete-Manriquez, 2011). The study presented that there is a week correlation between mainshock and aftershock frequency content. Furthermore, the predominant frequency of the aftershocks has an intensive effect on the behavior of the structures under seismic sequences. About the steel structures, the former study points out that, the drift demand does not increase significantly due to aftershocks if there is a big difference between the dominant frequency of vibration and the target structure. Hatzigeorgiou and Liolios studied the non-linear behavior of 8 different RC frames under repeated ground motions (Hatzigeorgiou \& Liolios, 2010). The paper presented that seismic sequences have a significant effect on the seismic 
response of RC structures. Characteristics of 184 real mainshock-aftershocks were studied by Ruiz-García (Ruiz-García, 2012). He showed that the predominant frequency of the mainshocks is fewer than their corresponding aftershocks and also the seismic behavior of the structures under artificial mainshock-aftershock is completely different from the real mainshockaftershock sequences. The damage of a single degree of freedom (SDOF) structure using inelastic analysis, four different hysteresis models, and three damage parameters were studied by Zhai et al. (Zhai et al., 2014). Mainshock-aftershock sequences scaled to different values of the ratio of aftershock to mainshock acceleration. They presented that slight ratios of aftershock to mainshock acceleration (under 0.5) have a negligible effect on the post mainshock response of the structures. In the following, Kim and Shin studied the seismic behavior of RC columns under seismic sequences loads using time history finite element analysis (Kim \& Shin, 2017). This study focused on the importance of a suitable selection of aftershocks for seismic sequences. Therefore, they developed an empirical relationship for the ratio of aftershock to mainshock horizontal pseudo-spectral accelerations in case of the real mainshock-aftershock sequences are not available. Amiri \& Bojórquez assessed the residual displacement ratio of a single degree of freedom (SDOF) structural system under mainshock-aftershock (Amiri \& Bojórquez, 2019). They proposed several equations to anticipate the residual displacement ratio under seismic sequences. A study about the effect of the seismic sequences on the dynamic behavior of an isolated nuclear power plant building was done (Zhao et al., 2020). In this regard, a finite analysis has been done using the 3D model. The study announced that, due to isolation, the effect of the aftershock on these types of structures is not remarkable.

To investigate the behavior of structures under mainshock-aftershock seismic sequences, a variety of studies have been done. However, most of the studies in this field focused on SDOF systems or 2D frames with a low height. Usually, 3D structures have been neglected due to the complexity of analysis and the design factors. The current paper studies the seismic behavior of 3D RC moment-resisting frame structures (RCMRFS) with a concrete shear wall system under real mainshockaftershock seismic sequences. In this regard, non-linear time history dynamic explicit finite element analysis was used. Two different height level structural models of three and six stories, respectively, were seismically loaded and designed according to the standard no. 2800 and ACI-318.The Etabs and Abaqus software were used to design and analysis of models respectively. The seismic behavior of the models was investigated under three real mainshock-aftershock seismic sequences of Friuli, Mammoth Lakes, and Cape Mendocino. To address this aim, seismic parameters of the drift ratio, the effect of the ratio of aftershock acceleration to mainshock acceleration, maximum relative displacement, residual displacement, maximum elastic-plastic strain were considered and compared in terms of the solely mainshock and mainshock-aftershock. Fig. 2 presents the research strategy implemented in this study.

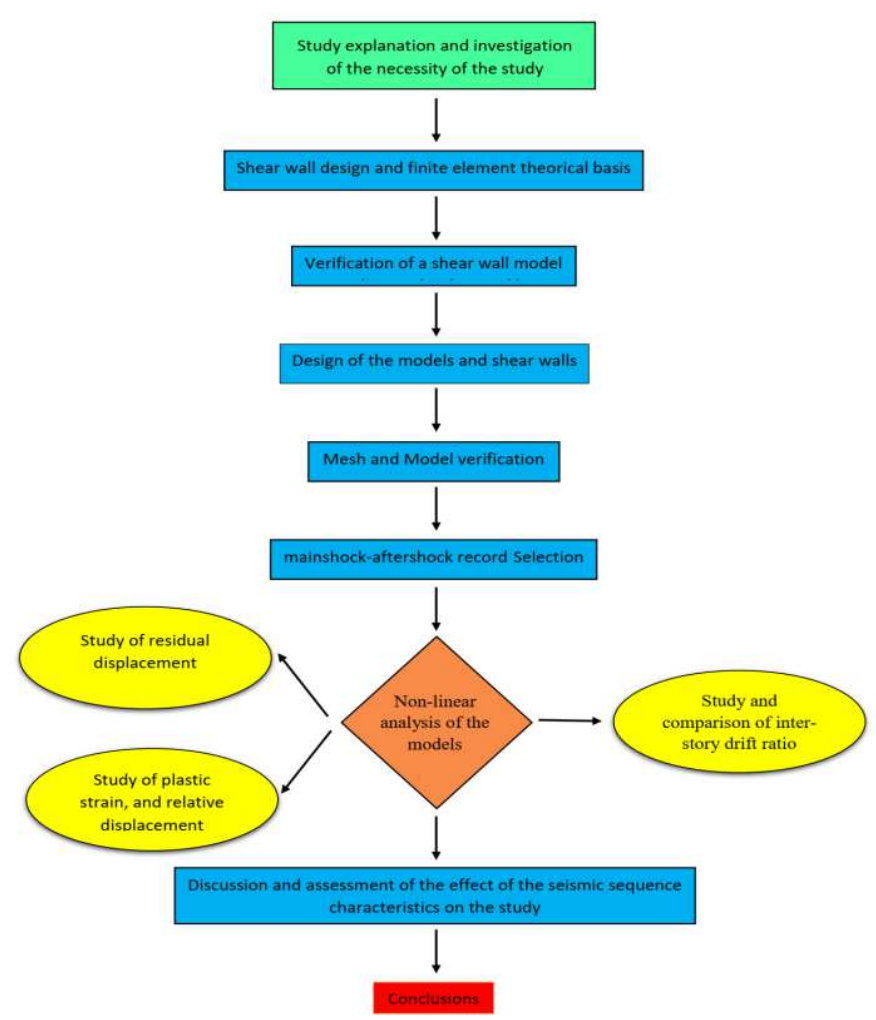

Fig. 2. Research flowchart 


\section{Theoretical Basis}

\subsection{Shear wall design}

In this study, the design of shear walls was done based on the Simple Tension \& Compression boundary element method ( $\mathrm{T} \& \mathrm{C}$ ). According to this method, it is assumed that the size of the boundary elements at the top and bottom (columns in this case) is fixed so the program does not adjust them. The software calculates the required steel rebars area in boundary members. In the end, the software algorithm checks that the reinforcing ratio to be less than the maximum allowable ratio. Finally, the minimum rebars will be used for the shear wall (Mostofinejad, 2008; Etabs tutorial, 2010; Shear Wall Design Manual ACI 318, 2017). Based on the load combinations the pier of the wall is designed for a factored axial force $\left(P_{f-t o p}\right)$ and a moment $\left(M_{\mathrm{f}-\text { top }}\right)$ (Etabs tutorial, 2010; Shear Wall Design Manual ACI 318, 2017). The applied moment and axial force will be converted to a tantamount force using Eqs. (1,2), also Similar equations apply at the bottom of the boundary elements (Etabs tutorial, 2010; Shear Wall Design Manual ACI 318, 2017).

$$
\begin{aligned}
& P_{\text {left-top }}=\frac{P_{f-t o p}}{2}+\frac{M_{f-t o p}}{\left(L_{p}-0.5 B_{1-l e f t}-0.5 B_{1-\text { right }}\right)} \\
& P_{\text {right }- \text { top }}=\frac{P_{f-\text { top }}}{2}-\frac{M_{f-\text { top }}}{\left(L_{p}-0.5 B_{1-l e f t}-0.5 B_{1-\text { right }}\right)}
\end{aligned}
$$

where $L_{p}$ is the wall length, respectively $B_{1-\text { left }}$ and $B_{1-\text { right }}$ are the width of the left and right boundary members.

Base on the loading pattern, the value of $P_{\text {left-top }}$ and $P_{\text {right-top }}$ could be tension or compression (negative or positive). In terms of tension, the required area of the steel rebar will be calculated using Eq. (3).

$$
A_{s t}=\frac{P}{\phi_{s} f_{y}}
$$

where $P$ is either $P_{\text {left-top }}$ or $P_{\text {right-top }}, A_{s t}$ is the needed area of steel reinforcement in concrete design, $\phi_{S}$ is the steel resistance factor, $\phi_{s}$ is the steel resistance factor and $f_{y}$ is the steel yield strength.

For the case of compression $\left(P_{\text {left-top }}\right.$ or $\left.P_{\text {right-top }}\right)$, the required area of steel rebars $\left(A_{s c}\right)$ has to satisfy the Eqs. (4 or 5) (Mostofinejad, 2008; Etabs tutorial, 2010; Shear Wall Design Manual ACI 318, 2017). Of note, for the negative values of $A_{s c}$ no compressive reinforcement is necessary while for all cases, the reinforcing ratio should be less than the maximum allowable ratio.

$$
\begin{gathered}
\text { Abs }(P)=\left(P_{\max \text { factor }}\right) \times\left[\phi_{c} f_{c}^{\prime}\left(A_{g}-A_{s c}\right)+\phi_{s} f_{y} A_{s c}\right] \\
A_{s c}=\frac{\frac{A b s(P)}{P_{\max \text { factor }}}-\phi_{c} f_{c}^{\prime} A_{g}}{\phi_{s} f_{y}-\phi_{c} f_{c}^{\prime}}
\end{gathered}
$$

where $P_{\max \text { factor }}$ is defined in the shear wall design preferences (the default is 0.80 ), $\phi_{c}$ is the concrete resistance factor for compression, $f_{c}^{\prime}$ is the concrete compressive strength, $A_{g}$ the gross area, equal to the total area ignoring any reinforcement and $A_{s c}$ is the area of steel reinforcement in concrete design.

\subsection{Finite element analysis}

The non-linear dynamic explicit finite element analysis based on the central-difference integration rule was used to study the seismic behavior of the models under mainshock-aftershock seismic sequences with a large number of small-time increments. The numerical implementation of the intended time integration method was explained in Eqs. (6-8) (Dassault Systèmes, 2017; Náprstek et al., 2011). To provide a realistic analysis, the structures were modeled as distributed mass. 
To consider the cumulative damage during the ground motion loading or also under seismic sequences (mainshockaftershock), both damage initiation criterion and damage evolution were characterized via yield strength (plastic strain for concrete) and the progressive degradation of the material stiffness (under a specific yield surface). For brittle materials like concrete, according to experimental studies, the compressive stiffness is completely recovered when the load changes from tension to compression so the stiffness recovery factor was considered equal to 1 . On the contrary, under tensile loading, the stiffness is not recovered due to small cracks so the stiffness recovery factor was considered equal to 0 (Lee \& Fenves, 1998; Lubliner, 1989; Hillerborg et al., 1976; Dassault Systèmes, 2017). Furthermore, the damage revolution in ductile materials (steel rebars) was defined based on the relative plastic displacement, and a specified exponential form using try and error (Hillerborg et al., 1976; Dassault Systèmes, 2017).

$$
\begin{gathered}
\dot{U}_{i+\frac{1}{2}}^{N}=\dot{U}_{i-\frac{1}{2}}^{N}+\frac{\Delta t_{(i+1)}+\Delta t_{i}}{2} \ddot{U}_{i}^{N} \\
U_{(i+1)}^{N}=U_{i}^{N}+\Delta t_{(i+1)} U_{l+\frac{1}{2}}^{\dot{N}} \\
\ddot{U}_{i}^{N}=\left(M^{N J}\right)^{-1}\left(P_{(i)}^{J}-I_{(i)}^{J}\right)
\end{gathered}
$$

Where $i$ corresponds to the increment number in an explicit dynamic step, $U_{i}^{N}$ is the displacement for the degree of freedom of $\mathrm{N}$ (a displacement or rotation component), $\dot{U}_{l}^{N}$ is the velocity for the degree of freedom of $\mathrm{N}$ (a displacement or rotation component), $\ddot{U}_{l}^{N}$ is the acceleration for the degree of freedom of $\mathrm{N}$ (a displacement or rotation component), $M^{N J}$ is the diagonal mass matrix, $P_{(i)}^{J}$ and $I_{(i)}^{J}$ are the external and the internal load vector respectively.

\section{Methodology}

\subsection{Verification}

The verification was done over two sections. The non-linear FE analysis results were compared with the results of an experimental study conducted by Thomson and Wallace (Thomsen \& Wallace, 2004).

Firstly: As shown in Table 1, the top displacement $(\boldsymbol{\Delta})$ of the shear wall model (RW1) was calculated under the lateral load $\left(\mathbf{F}_{\max }\right)$ of $141 \mathrm{kN}$ and compared with the experimental model under the same load.

Table 1. Top displacement of the shear wall model under $141 \mathrm{kN}$ lateral load

\begin{tabular}{|c|c|c|c|}
\hline Model & $\mathbf{F}_{\mathbf{m a x}}(\mathbf{k N})$ & $\boldsymbol{\Delta}_{\mathbf{m a x}}(\mathbf{m m})$ & $\overline{\mathbf{\Delta}}$ \\
\hline Experimental (Thomsen and Wallace) & 141.00 & 69.90 & 0.0191 \\
\hline Finite element (this study) & 141.00 & 67.63 & 0.0184 \\
\hline
\end{tabular}

Secondly: To study the non-linear cyclic behavior of the FE model, the intended shear wall model was analyzed under cyclic displacement as illustrated in Fig. 3a. The maximum reaction force (base shear) due to cyclic loading $\left(F_{c}^{n}\right)$ was compared (Table 2) with the same parameter of the experimental study of Thomson and Wallace (Thomsen \& Wallace, 2004). Fig. 3b shows the base shear- cycle number of the FE model under cyclic displacement protocol.

Comparing the results of the experimental and the FE model in both former verification cases, there is a good agreement between the results (under 5\% error in both cases). 


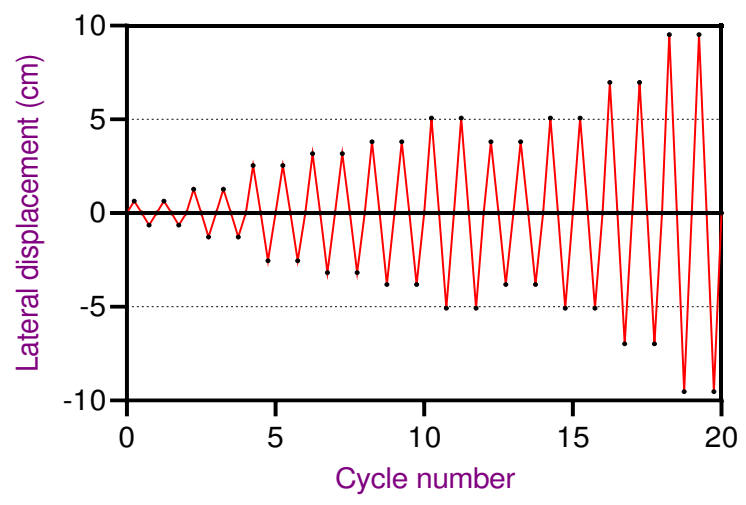

(a)

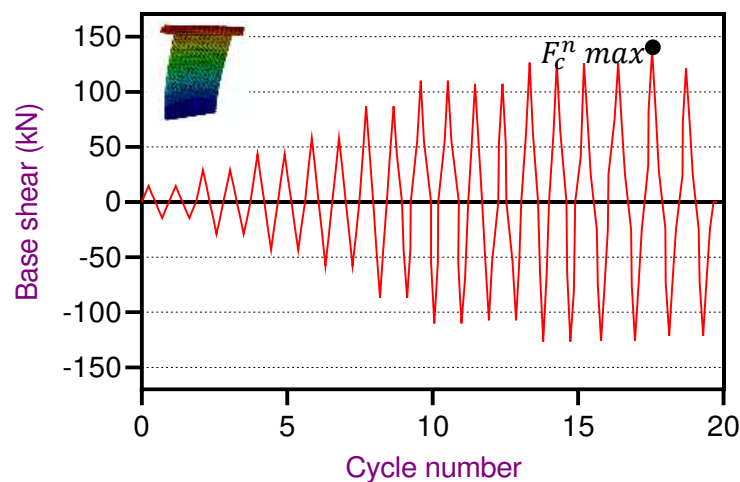

(b)

Fig. 3. Cyclic behavior of RW1 FE model: (a) applied displacement protocol (b) base shear

Table 2. The maximum shear force of the RW1 model due to cyclic displacement protocol

\begin{tabular}{|c|c|}
\hline Model & $\mathbf{F}_{\mathbf{c}}^{\mathbf{n}}(\mathbf{k N})$ \\
\hline Experimental & 131.00 \\
\hline Finite element & 137.63 \\
\hline
\end{tabular}

\subsection{Design of the models}

To study the seismic behavior of the models under seismic sequences, two models with different high levels and residential use (Important factor=1) in an area with a high seismic hazard $(\mathrm{Ag}=0.35 \mathrm{~g})$ were designed using Etabs software. Fig. 4 and Table 3 respectively show the plan view and the specification of the models. 


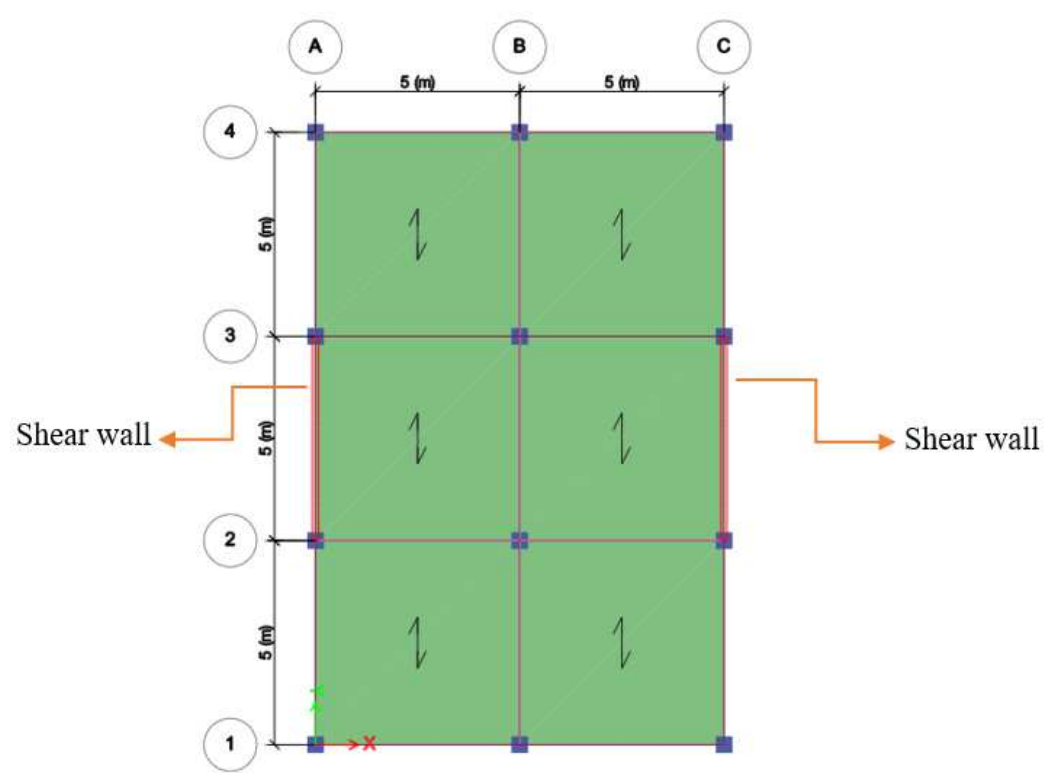

Fig. 4. Plan view of the models

Table 4. Models Specification

\begin{tabular}{|c|c|c|}
\hline Model No. & Number of floors & Height of the model (m) \\
\hline 1 & 3 & 9.00 \\
\hline 2 & 6 & 18.00 \\
\hline
\end{tabular}

The seismic loading and design of the studied models were done according to standard No.2800 ACI 318 respectively (Standard No. 2800, 2015; ACI 318-14, 2014). In the X-direction, the frame system is an intermediate moment-resisting frame (response modification=5) also in the $\mathrm{Y}$-direction, the structure system is an intermediate moment resisting frame with the shear wall (response modification=6). Shear walls were located between two axes of 2 and 3 . The site-soil has the following characteristics: $S=1.5, T_{S}=0.5, T_{0}=0.1,375 \mathrm{~m} / \mathrm{s}<\mathrm{V}_{\mathrm{s}}<750 \mathrm{~m} / \mathrm{s}$ which is match to the selected mainshockaftershock records soil type (section 3.5). The type of rebars and concrete were considered as AIII and M30 with yield strength $\left(f_{y}\right)$ of $400 \mathrm{MPa}$ and compressive strength $\left(f^{\prime}{ }_{c}\right)$ of $30 \mathrm{MPa}$ respectively. Fig. 5 and Tables 4,5 respectively present the $3 \mathrm{D}$ view of the structural models and details of the designed shear walls.

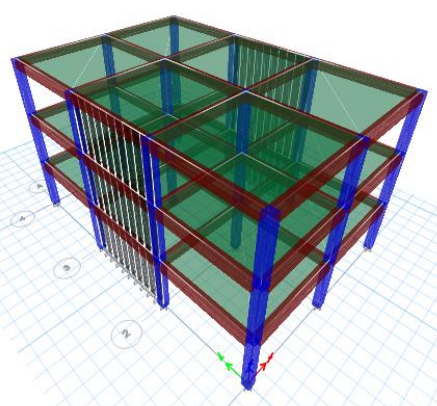

(a)

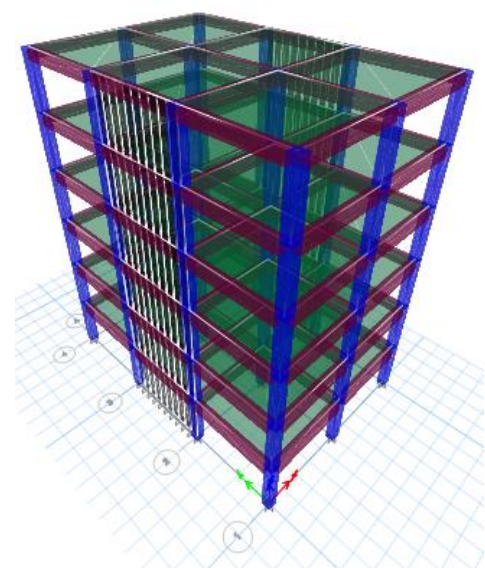

(b)

Fig. 5. Designed structural models: (a) three-story (b) six-story 
Table 4. Shear walls and boundary members details of the three-story structural model

\begin{tabular}{|c|c|c|}
\hline Story No. & Columns (boundary members) & Shear walls \\
\hline 1 & $\mathrm{C} 40 \times 40-12 Ф 20$ & 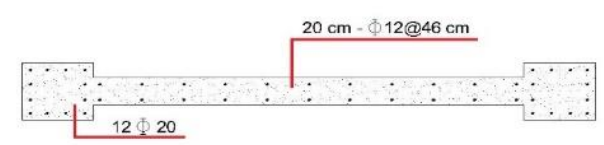 \\
\hline 2 & $\mathrm{C} 40 \times 40-12 \Phi 16$ & $\because \vdots \quad \vdots \quad \vdots \quad T^{15 \mathrm{~cm}-\Phi 12 @ 55 \mathrm{~cm}}$ \\
\hline 3 & $\mathrm{C} 40 \times 40-12 \Phi 14$ & 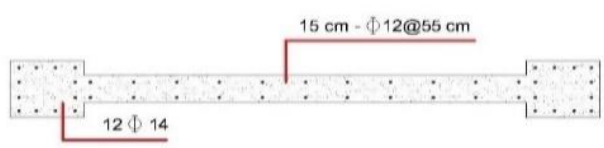 \\
\hline
\end{tabular}

Table 5. Shear walls and boundary members details of the six-story structural model

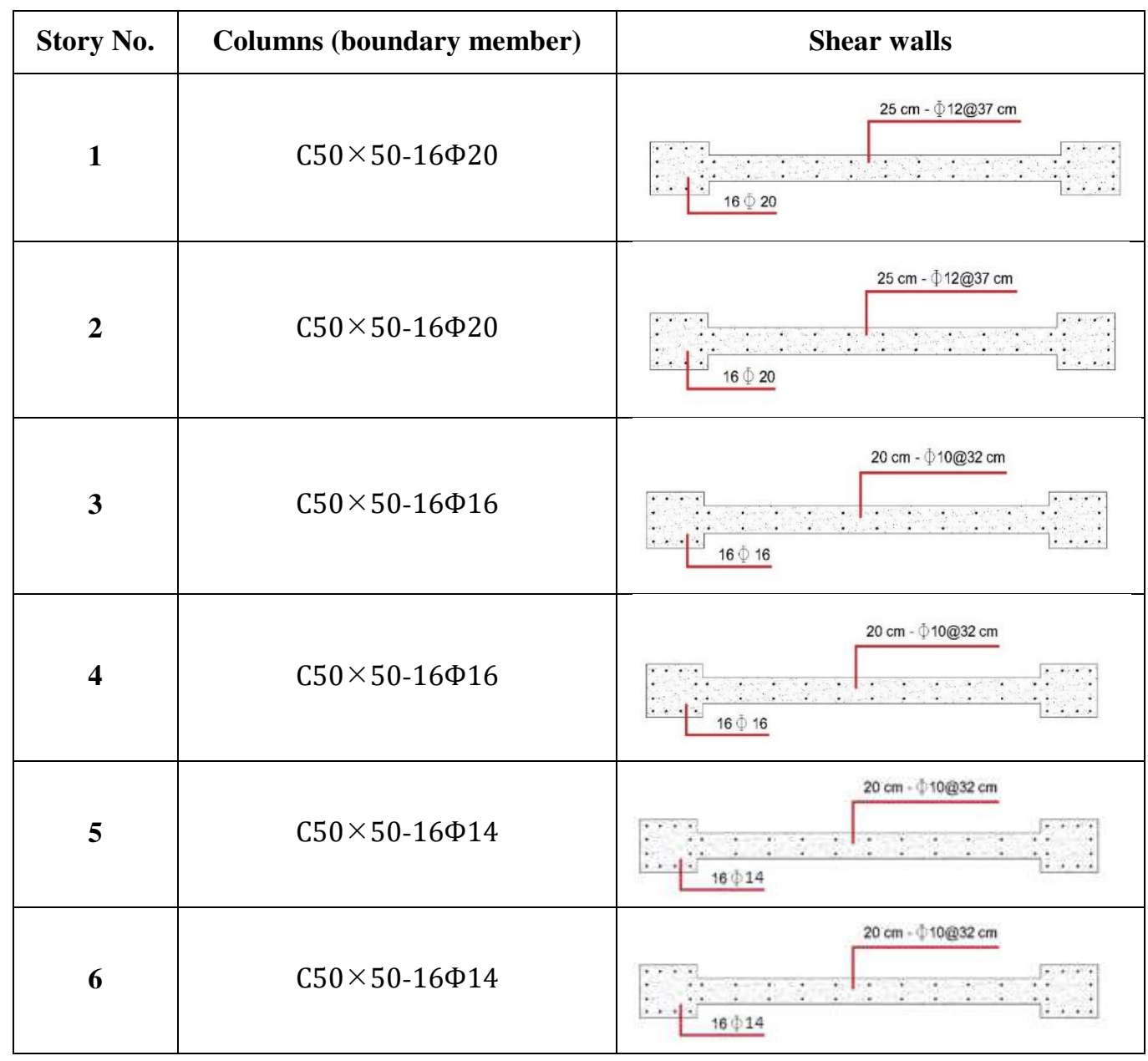




\subsection{Analytical model}

Respectively, structures were designed and analyzed using Etabs and Abaqus software for non-linear FE analysis. To simulate the tensile behavior of concrete, a strain-stress diagram was calculated (Fig. 6) based on the Hsu, L. S. and Carreira and Chu studies (Hsu \& Hsu, 2015; Carreira \& Chu, 1986).

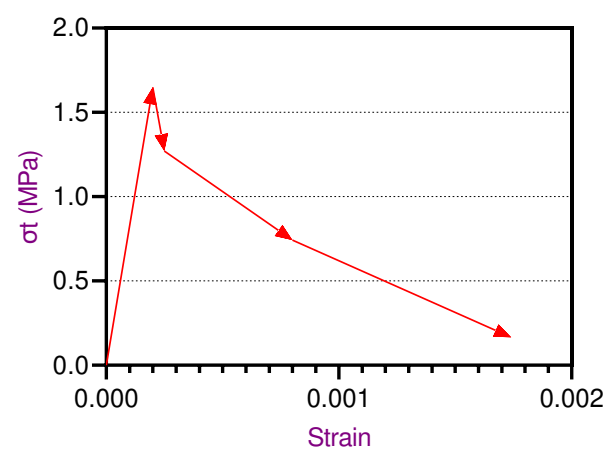

Fig. 6. Concrete tensile stress-strain behavior

The stress-strain behavior of concrete in compression was calculated using Eqs. (9-12) which have been presented and verified experimentally by Hsu, L. S. (Hsu \& Hsu, 2015). The former behavior can be used for concrete with compressive strength up to $62 \mathrm{MPa}$. Fig. 7 shows the compressive stress-strain diagram of concrete. The parameters of $\sigma_{c}, \sigma_{c u}$ and $E_{0}$ are in unit of kip/in ${ }^{2}\left(1 \mathrm{MPa}=0.145 \mathrm{kip} / \mathrm{in}^{2}\right)$.

$$
\begin{gathered}
\sigma_{c}=\left(\frac{\beta\left(\frac{\varepsilon_{c}}{\varepsilon_{0}}\right)}{\beta-1+\left(\frac{\varepsilon_{c}}{\varepsilon_{0}}\right)^{\beta}}\right) \sigma_{c u} \\
\beta=\frac{1}{1-\left(\frac{\sigma_{c u}}{\varepsilon_{0} E_{0}}\right)} \\
\varepsilon_{0}=8.9 \times 10^{-5} \sigma_{\mathrm{cu}}+3.28312 \times 10^{3} \\
\mathrm{E}_{0}=1.2431 \times 10^{2} \sigma_{\mathrm{cu}}+3.28312 \times 10^{3}
\end{gathered}
$$

Where $\sigma_{c}$ is the calculated compressive stress, $\sigma_{c u}$ is the ultimate compressive stress, $\mathrm{E}_{0}$ is the Young modulus and $\varepsilon_{c}$ is the concrete compressive strain.

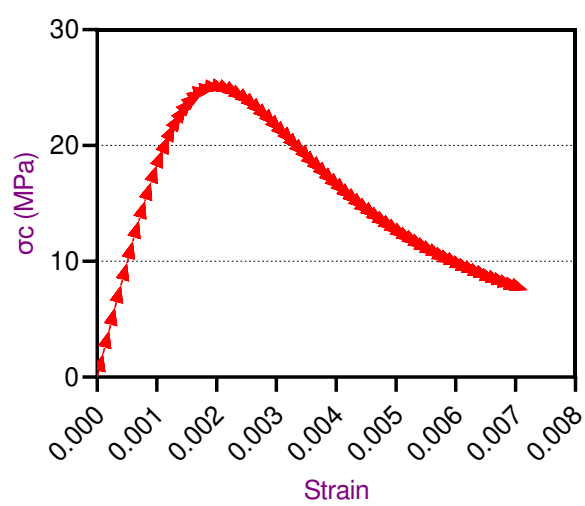

Fig. 7. Concrete compressive stress-strain behavior 
The stress-strain behavior of steel rebars was calculated based on the Ramberg-Osgood equation (Eqs. 13-15) which is especially useful for metals that harden with plastic deformation like steel (Ramberg \& Osgood, 1943).

$$
\begin{gathered}
\varepsilon=\frac{\sigma}{E}+K\left(\frac{\sigma}{E}\right)^{n} \\
\varepsilon_{u s}=100\left(\varepsilon_{r}-\frac{F_{t u}}{E}\right) \\
n=\frac{\ln \frac{\varepsilon_{u s}}{0.2}}{\ln \frac{F_{t u}}{F_{t y}}}
\end{gathered}
$$

where $\sigma$ is the stress (maximum = ultimate tensile stress), $\varepsilon$ is the calculated steel material strain, $F_{t u}$ is the ultimate strength of the steel, $F_{t y}$ is the yield strength of the steel, $\varepsilon_{r}$ is the plastic strain at $F_{t u}$ and $K$ is a constant, depends on the material being considered ( 0.002 in this study).

The concrete damage plasticity model was used to simulate the behavior of concrete elements under arbitrary loading. The model is a continuum, plasticity-based, damage model for concrete or brittle materials also it has the potential to perform the plastic behavior of the concrete in both tensile and compression by considering the strength and stiffness degradation (damage) under cycle loading (like seismic loading). Furthermore, the former model has a good ability to consider the interaction between concrete and rebars [Dassault Systèmes, 2017; Wahalathantri et al., 2011; Lee \& Fenves, 1998). The FE analytical models illustrated in Figs. 8a,b.

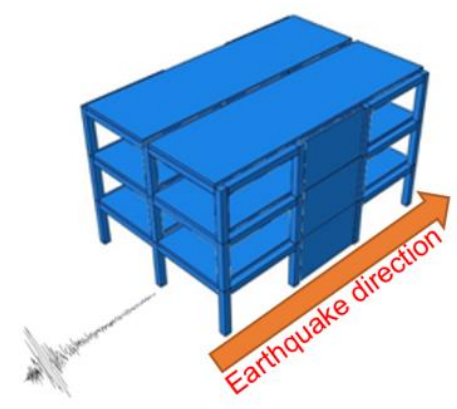

(a)

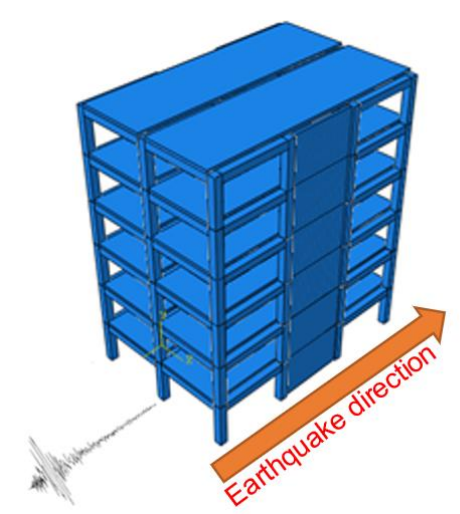

(b)

Fig. 8. Abaqus analytical models: (a) Three-story (b) Six-story

\subsection{Mesh generation}

In this case, according to the analytical and geometric conditions, the 4-node linear tetrahedron and 2-node linear 3-D truss mesh elements were selected for the concrete and steel rebar materials respectively (Johnson, 2006). To achieve the best mesh size, the six-story model was analyzed with different mesh element sizes using the Frequency-AMS analysis. The optimal element size was obtained from comparing the former results with the fundamental period calculated by code No.2800 $(0.67 \mathrm{sec}$ ) (Standard No. 2800, 2015). Table 5 shows the calculated fundamental period of the intended model in different mesh element sizes. According to the results (Table 5), by increasing the element size to $2.00 \mathrm{~m}$, the calculated fundamental period diverges from the other cases $(1.00 \mathrm{~m}, 0.50 \mathrm{~m}$, and $0.25 \mathrm{~m})$. Therefore, the optimum element size of $1.00 \mathrm{~m}$ was chosen for this study. 
Table 5. Fundamental period of the six-story model with the different mesh element sizes

\begin{tabular}{|c|c|c|}
\hline Mesh element size (m) & Number of mesh elements & Fundamental period of the model (s) \\
\hline 0.25 & 254,919 & 0.608 \\
\hline 0.50 & 38,862 & 0.600 \\
\hline 1.00 & 15,004 & 0.600 \\
\hline 2.00 & 5,323 & 0.420 \\
\hline
\end{tabular}

\subsection{Mainshock-aftershock records}

To investigate the seismic behavior of the models under seismic sequences, real mainshock-aftershock acceleration records were chosen from the PEER database (Pacific Earthquake Engineering Research Center, 2011). The main idea for finding aftershocks is to use seismic declustering methods (independent-dependent), which are empirically determined by the sequences of previous earthquakes data and measurement of space-time history (Hainzl \& Steacy, 2010).

The shear wave velocity of ground motion records agrees with the seismic design assumptions $\left(375<V_{s}(\mathrm{~m} / \mathrm{s})<750\right)$. Furthermore, a 5-second zero acceleration interval between mainshock and aftershock (time gap) was considered (Pirooz et al., 2021). To provide a comprehensive evaluation of the behavior of structures under seismic sequences, an effort has been made that selected records have a different ratio of aftershock to mainshock acceleration, frequency content, and magnitude. The specifications, acceleration time-history, and response acceleration spectra of the intended mainshock-aftershock ground motions were shown in Table 6 and Figs. 9-11.

Table 6. Specifications of ground motion records

\begin{tabular}{|c|c|c|c|c|}
\hline Event & Event & Date & Magnitude $\left(M_{W}\right)$ & PGA(g) \\
\hline Friuli-Italy (Mainshock) & \multirow{2}{*}{ Tolmezzo } & $1976 / 05 / 06$ & 6.5 & 0.35 \\
\hline Friuli-Italy (Aftershock) & & $1976 / 05 / 07$ & 5.2 & 0.11 \\
\hline Cape Mendocino (Mainshock) & \multirow{2}{*}{ Petrolia } & $1992 / 04 / 25$ & 7.1 & 0.66 \\
\hline Cape Mendocino (Aftershock) & & $1992 / 04 / 26$ & 6.6 & 0.49 \\
\hline Mammoth Lakes (Mainshock) & \multirow{2}{*}{ Convict Creek } & $1980 / 05 / 25$ & 6.6 & 0.42 \\
\hline Mammoth Lakes (Aftershock) & & $1980 / 05 / 25$ & 5.7 & 0.37 \\
\hline
\end{tabular}

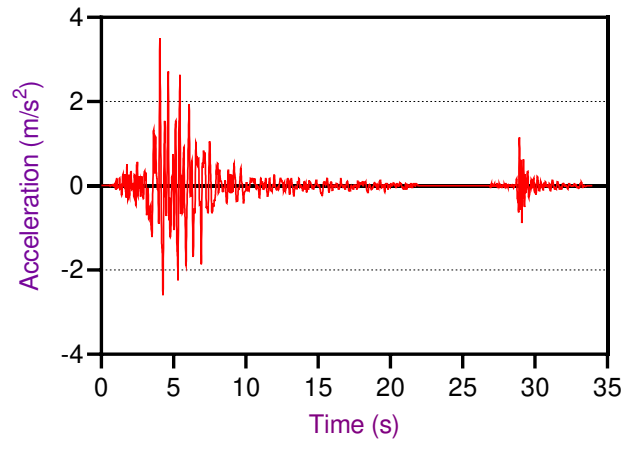

(a)

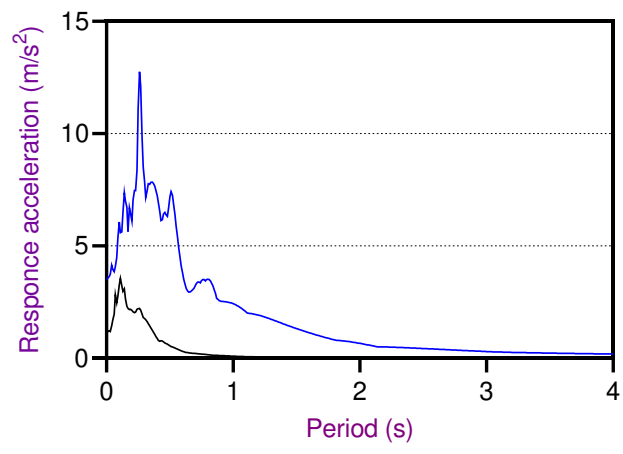

(b)

Mainshock

Fig. 9. Friuli mainshock-aftershock: (a) Acceleration record (b) Response acceleration spectra 


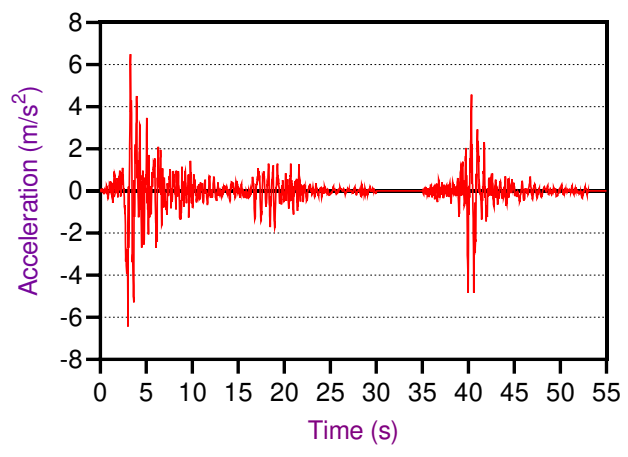

(a)

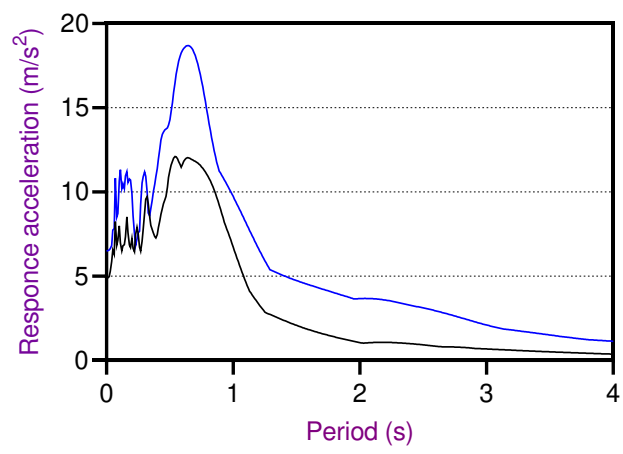

(b)

Mainshock

Aftershock

Fig. 10. Cape Mendocino mainshock-aftershock: (a) Acceleration record (b) Response acceleration spectra

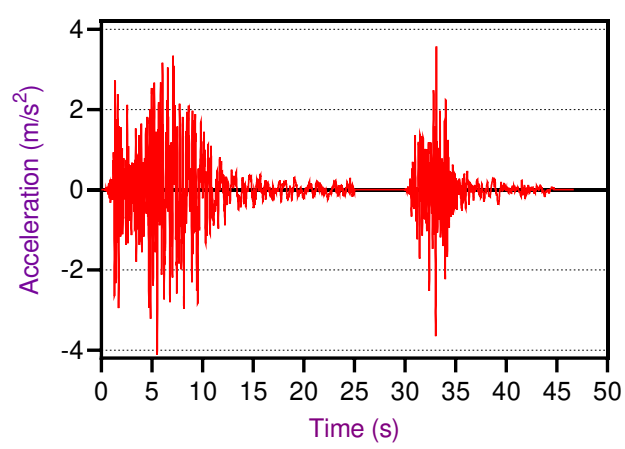

(a)

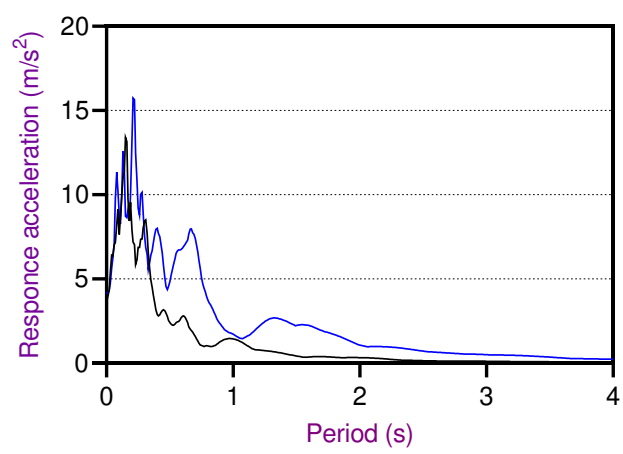

(b)

Mainshock

Aftershock

Fig. 11. Mammoth Lakes mainshock-aftershock: (a) Acceleration record (b) Response acceleration spectra

\section{Analysis results}

\subsection{Relative displacement}

According to previous studies, under seismic loading, shear wall systems can reduce relative displacement up to $70 \%$ (Astaneh-As1, 2002; Mostofinejad, 2008). Different design codes, limit the top displacement of shear wall systems between $H / 50$ to $H / 2000$ (Khouri, 2011).

\subsubsection{The three-story model}

Under three mainshock-aftershocks of Friuli, Cape Mendocino, and Mammoth Lakes, the maximum relative displacements of the intended model were calculated respectively $0.72 \mathrm{~cm}, 1.48 \mathrm{~cm}$, and $1.68 \mathrm{~cm}$. The roof relative displacement time-history of the model was shown in Figs. 12a,b,c. Due to the high lateral stiffness of the shear wall system (for low-rise structures), the model shows completely elastic behavior (plastic strain=0) under all three seismic sequences. Furthermore, aftershocks cause no displacement growth in this case. In other words, it may there is no need to consider seismic sequences in the design of short structures (low rise) with a shear wall system. Table 7 shows some results of the three-story model analysis. 
Table 7. Results of the three-story model analysis

\begin{tabular}{|c|c|c|c|c|c|}
\hline Event & $u_{M A X_{M a i n s h o c k}}(\mathrm{~cm})$ & $u_{M A X_{M a i n s h o c k-A f t e r s h o c k}}(\mathrm{~cm})$ & $\boldsymbol{u}$ & $S_{\max l}$ & $P S_{\max }$ \\
\hline Friuli & 0.72 & 0.72 & $\frac{H}{1250}$ & $2.09 \mathrm{e}-4$ & 0.0 \\
\hline Cape Mendocino & 1.48 & 1.48 & $\frac{H}{608}$ & $4.43 e-4$ & 0.0 \\
\hline Mammoth lakes & 1.68 & 1.68 & $\frac{H}{535}$ & $4.98 \mathrm{e}-4$ & 0.0 \\
\hline
\end{tabular}

Where $u_{M A X_{\text {Mainshock }}}$ is the roof maximum relative displacement under mainshock, $u_{M A X_{M a i n s h o c k-A f t e r s h o c k}}$ is the roof maximum relative displacement under mainshock-aftershock, $S_{\max l}$ is the maximum logarithmic strain and $P S_{\max }$ is the maximum plastic strain.

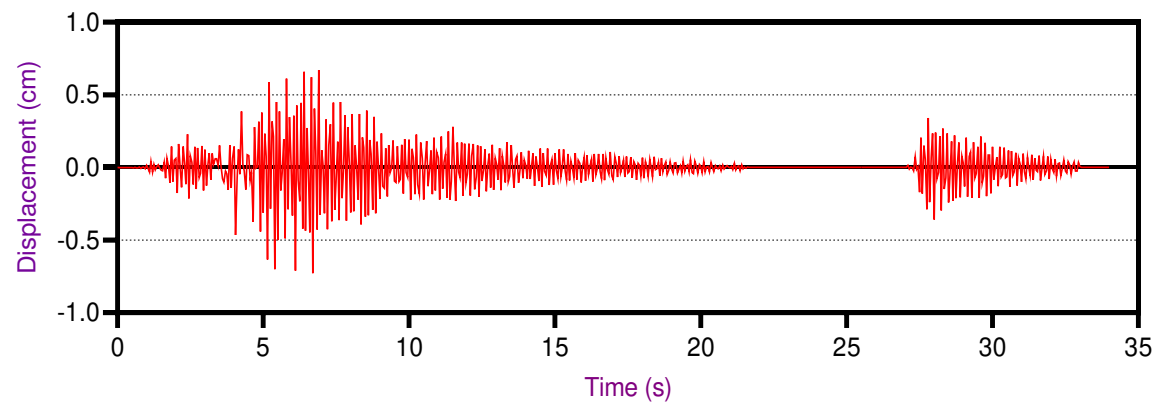

(a)

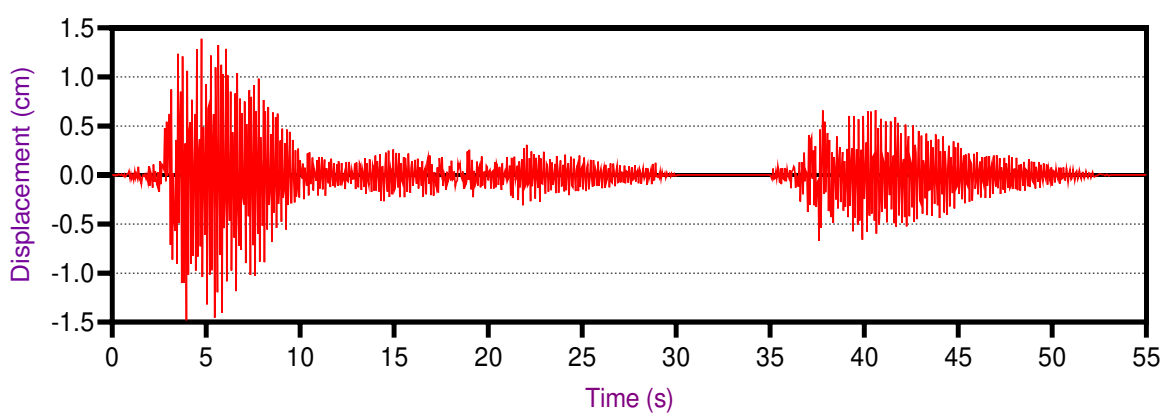

(b)

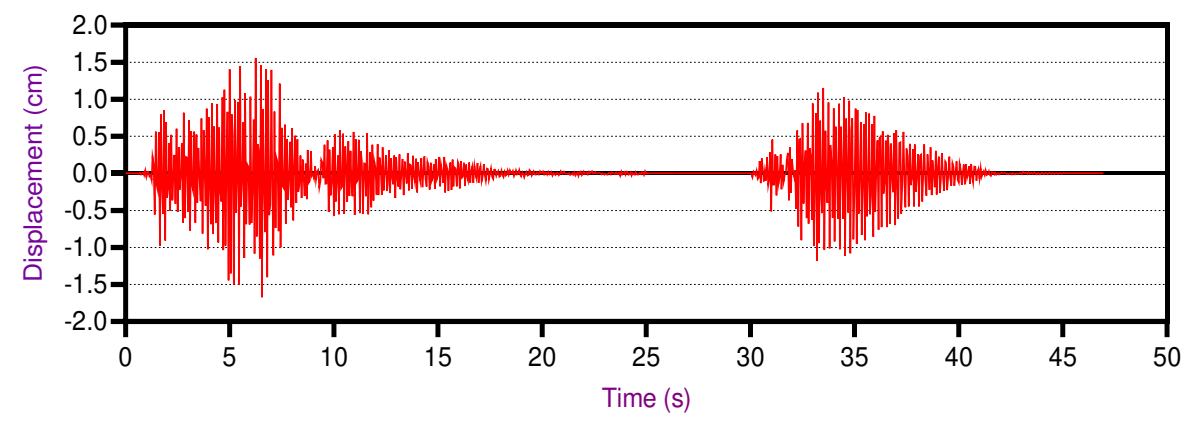

(c)

Fig. 12. The roof relative displacement of the three-story model under mainshock-aftershock: (a) Friuli (b) Cape Mendocino (c) Mammoth Lakes 


\subsubsection{The six-story model}

The six-story model (mid-rise) seismic analysis, under mainshock-aftershock, shows completely different seismic behavior compared to the three-story model. During the Friuli mainshock, the first floor undergoes from elastic to plastic behavior (Fig. 13) while the plastic strain does not increase or grow under the aftershock. Therefore, under the Friuli mainshock-aftershock, the seismic behavior of the model is not susceptible to seismic. In other words, the aftershock causes no growth in residual displacement.

Like the former case, under the Cape Mendocino mainshock-aftershock, the model shows plastic behavior (or residual displacement) on the first floor however the aftershock causes a significant growth in the amount of relative displacement as well as the residual displacement. The seismic sequence increases the maximum relative displacement up to $21.31 \%$ compared to only the mainshock. Furthermore, the residual displacement grows almost $21 \%$ which is remarkable.

The seismic behavior of the six-story model under the Mammoth Lakes seismic sequence is similar to the Cape Mendocino mainshock-aftershock. Due to aftershock, the maximum relative displacement and residual displacement respectively increase around $\mathbf{2 7 . 9 7 \%}$ and $55.61 \%$ (in comparison with considering only the mainshock). The six-story model relative roof displacements and some results of the analysis were illustrated in Figs. 14a,b,c, and Table 8 respectively.

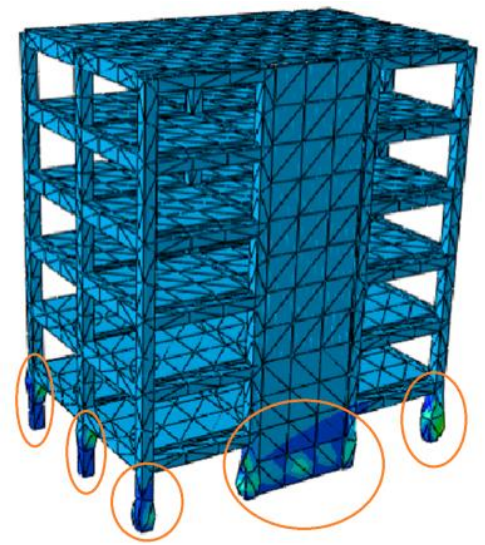

Fig. 13. Place of plastic strain under the Friuli mainshock-aftershock

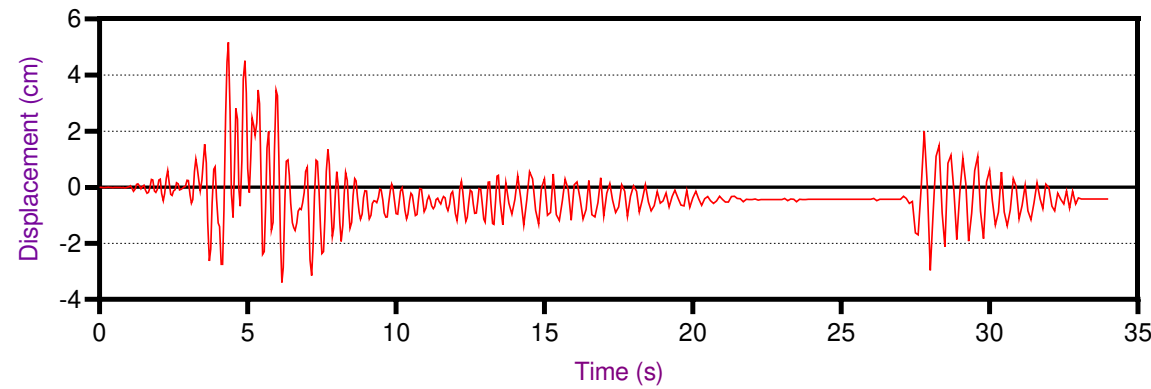

(a) 


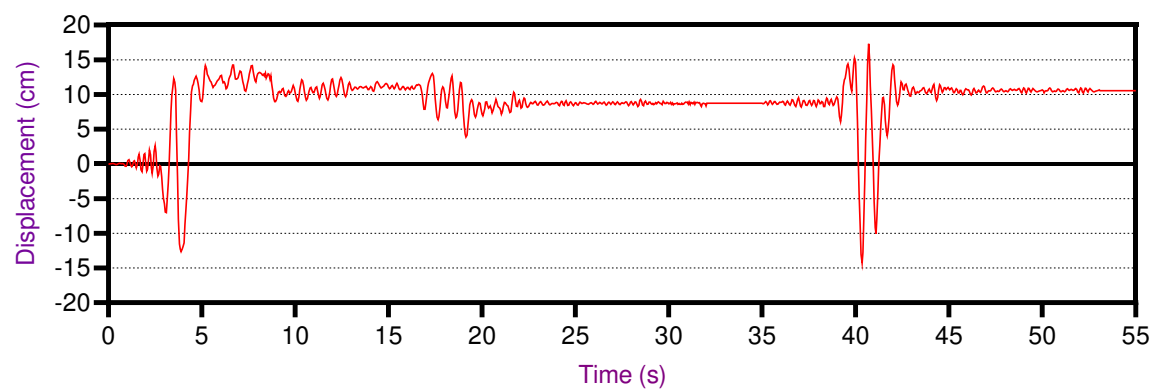

(b)

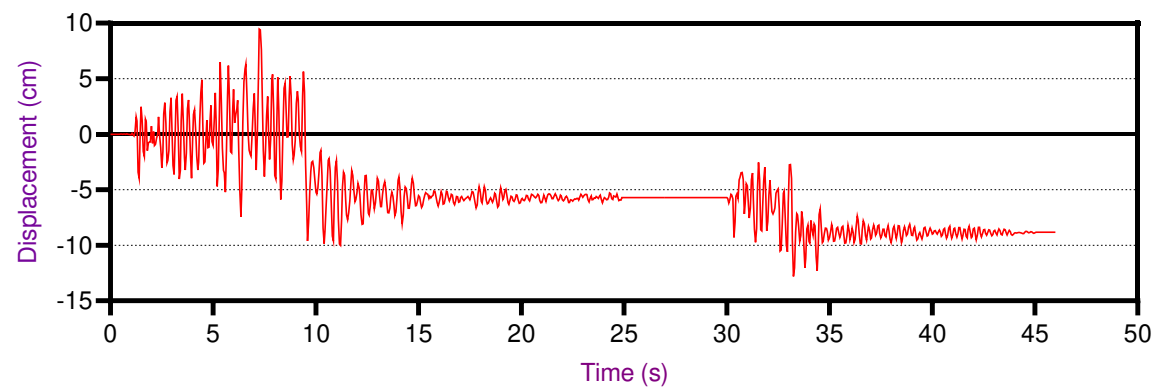

(c)

Fig. 14. The roof relative displacement of the six-story model under mainshock-aftershock: (a) Friuli (b) Cape Mendocino (c) Mammoth Lakes

Table 8 .The results of the six-story model analysis

\begin{tabular}{|c|c|c|c|c|c|}
\hline Event & $\boldsymbol{u}_{\text {MAX }}$ Mainshock & $\boldsymbol{c}$ & $\boldsymbol{u}_{\text {MAX }}$ Mainshock-Aftershock \\
\hline Friuli & 5.12 & 5.12 & $\frac{H}{347}$ & $1.02 \mathrm{e}-3$ & $0.86 \mathrm{e}-4$ \\
\hline Cape Mendocino & 14.20 & 17.30 & $\frac{H}{126}$ & $5.80 \mathrm{e}-3$ & $1.78 \mathrm{e}-4$ \\
\hline Mammoth lakes & 10.00 & 12.81 & $\frac{H}{179}$ & $4.08 \mathrm{e}-3$ & $1.23 \mathrm{e}-4$ \\
\hline
\end{tabular}

\subsection{Inter-story drift ratio}

As a valuable and important index to evaluate the seismic behavior of structures with all types of structural system or height, the inter-story drift ratio was considered in the current study as a standard for judging the seismic behavior of the structures under seismic sequences (Zhou et al., 2012).

\subsubsection{Inter-story drift ratio of the three-story model}

As maintained in section 4.1.1, aftershocks cause no growth in relative displacements of the three-story model compared to mainshocks. Therefore, in this case, there is no difference between the mainshock and the mainshock-aftershock drift ratio diagrams which can also be seen in Figs. 15a,b,c. 


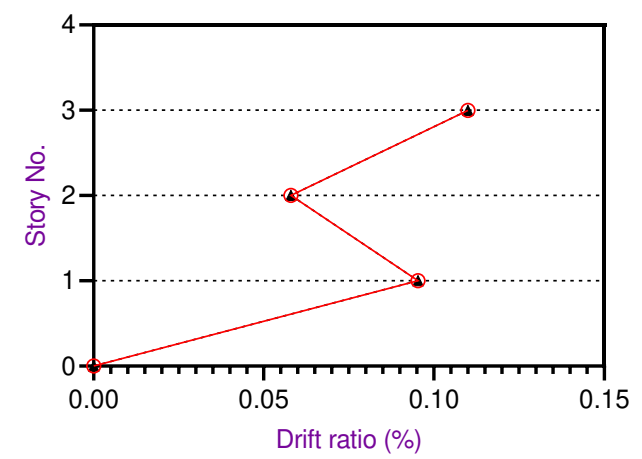

(a)

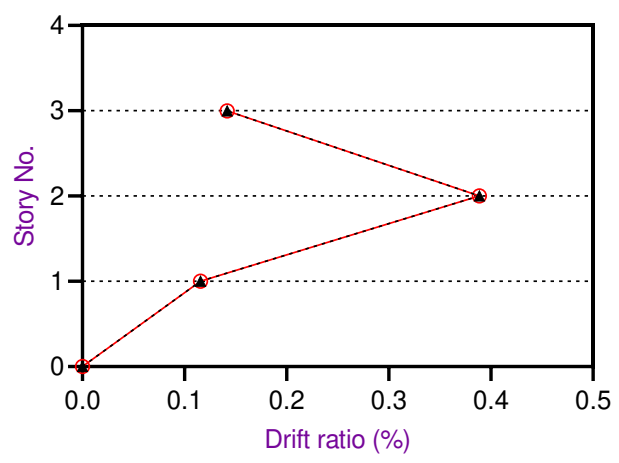

(c)

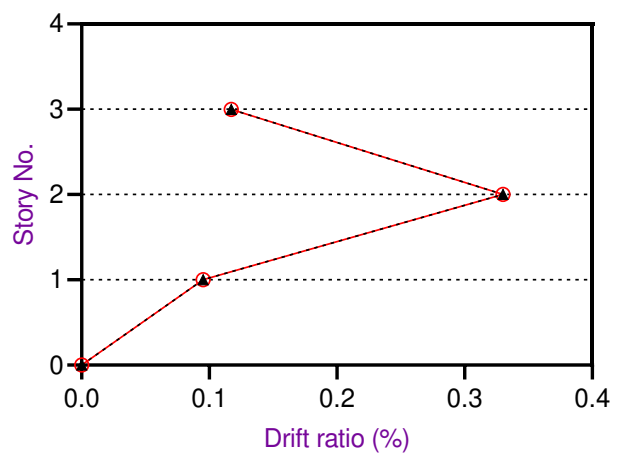

(b)

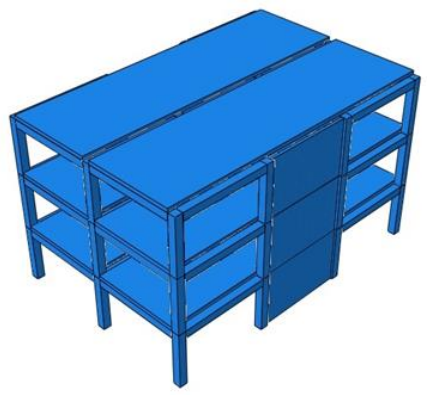

Mainshock

Mainshock-aftershock

Fig. 15. Three-story model drift ratio under mainshock-aftershock: (a) Friuli (b) Cape Mendocino (c) Mammoth Lakes

\subsubsection{Inter-story drift ratio of the six-story model}

Investigation of the six-story drift ratio under an earthquake with a slight aftershock like Friuli (Fig. 16a) shows that there will be no significant growth in the drift ratio due to seismic sequence (aftershock) while this model shows plastic behavior on the first floor under the Friuli mainshock. Indeed, there is no difference between drift ratio diagrams under mainshock and mainshock-aftershock. On the other hand, the behavior of this model under aftershocks of Cape Mendocino and Mammoth lakes shows a significant growth in the drift ratio which is clear in Figs. 16b,c. According to the drift ratio diagrams (Figs. 16a,b,c), unlike the behavior of the low to midrise moment-resisting frame structures under seismic sequences which the drift ratio usually grows with the increase in the height (Hosseini et al., 2019; Ruiz-García et al., 2012; Hatzivassiliou \& Hatzigeorgiou, 2015), in structures with shear wall structural system (this study), this parameter does not grow significantly. In the low to mid-rise shear wall structures, the maximum amount of drift growth is related to the first floor. 


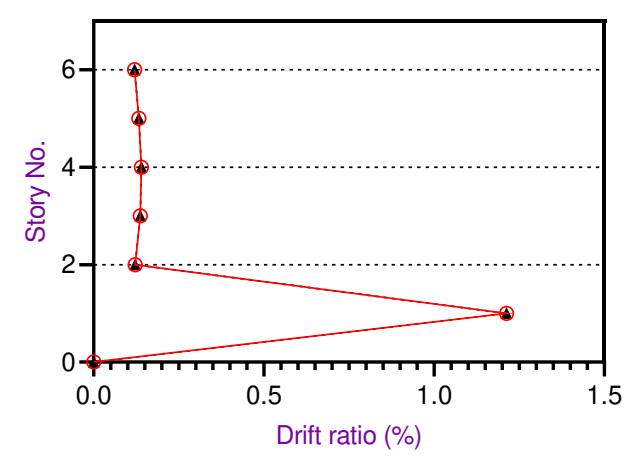

(a)

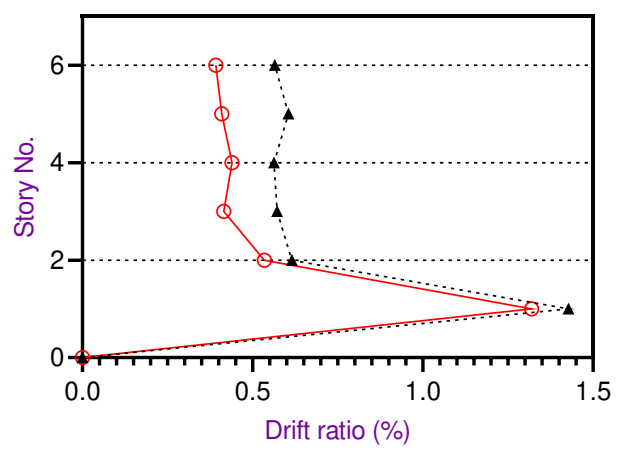

(c)

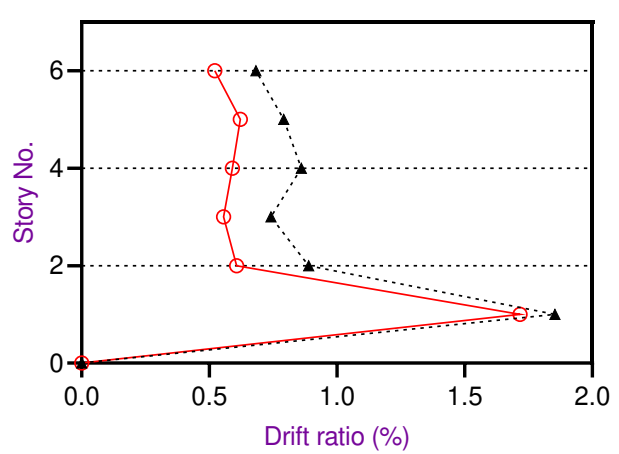

(b)

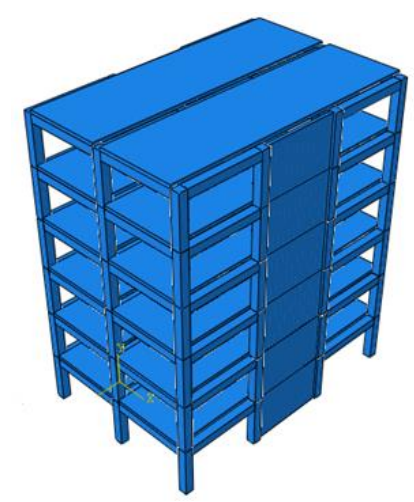

Mainshock

Mainshock-aftershock

Fig. 16. Six-story model drift ratio under mainshock-aftershock: (a) Friuli (b) Cape Mendocino (c) Mammoth Lakes

\subsection{Residual displacement}

The comparison between the residual displacement of two models under mainshock and mainshock-aftershock shows that the seismic sequences may remarkably increase this parameter even more than $50 \%$ in the medium height structure. Roof residual displacements of the models under seismic sequences were shown in Tables 9,10.

Table 9. Maximum residual displacement of the three-story model under mainshock and mainshock-aftershock

\begin{tabular}{|c|c|c|c|}
\hline Event & $\begin{array}{c}\text { Mainshock maximum } \\
\text { residual displacement }(\mathbf{c m})\end{array}$ & $\begin{array}{c}\text { Mainshock-aftershock maximum } \\
\text { residual displacement }(\mathbf{c m})\end{array}$ & Increase (\%) \\
\hline Friuli & 0.0 & 0.0 & 0.0 \\
\hline Cape Mendocino & 0.0 & 0.0 & 0.0 \\
\hline Mammoth Lakes & 0.0 & 0.0 & 0.0 \\
\hline
\end{tabular}

Table 10. Maximum residual displacement of the six-story model under mainshock and mainshock-aftershock

\begin{tabular}{|c|c|c|c|}
\hline Event & $\begin{array}{c}\text { Mainshock maximum residual } \\
\text { displacement }(\mathbf{c m})\end{array}$ & $\begin{array}{c}\text { Mainshock-aftershock maximum } \\
\text { residual displacement }(\mathbf{c m})\end{array}$ & Increase (\%) \\
\hline Friuli & 0.47 & 0.47 & 0.0 \\
\hline Cape Mendocino & 8.73 & 10.56 & 20.96 \\
\hline Mammoth Lakes & 5.70 & 8.87 & 55.61 \\
\hline
\end{tabular}




\section{Discussion}

By comparing the maximum relative displacement of two models under mainshock-aftershock seismic sequences, it concludes that this parameter is not always related to the PGA and magnitude. The maximum relative displacement of the three-story model is related to the Mammoth Lakes earthquake (13.51\% more than Cape Mendocino ground motion), while the PGA of this earthquake is about $58 \%$ less than the Cape Mendocino earthquake. On the other hand, in the case of the six-story model, the maximum relative displacement under the Cape Mendocino mainshock is $29.80 \%$ greater than the Mammoth Lakes mainshock. Therefore, it can be inferred that other factors such as frequency content, response acceleration spectrum (Figs. 9-11), fundamental period of the structure, amount of earthquake energy, and also energy release procedure are effective in the behavior of structures under seismic sequences. The cumulative energy diagrams of the intended ground motions were shown in Figs. 17a,b,c.

In addition, the ratio of aftershock acceleration to mainshock acceleration is a determinative factor in the behavior of structures under seismic sequences. The Friuli aftershock causes no growth in drift ratio, residual, and relative displacement, thus the reason for this behavior could be a low ratio of aftershock acceleration to mainshock acceleration (0.3). On the other hand, due to the high ratio of this factor in Cape Mendocino and Mammoth Lakes ground motions ( 0.80 and 0.74 respectively) aftershocks cause remarkable growth in relative and residual displacements. For instance, relative displacements grow $21.31 \%$ and $27.97 \%$ respectively under Cape Mendocino and Mammoth Lakes aftershocks.

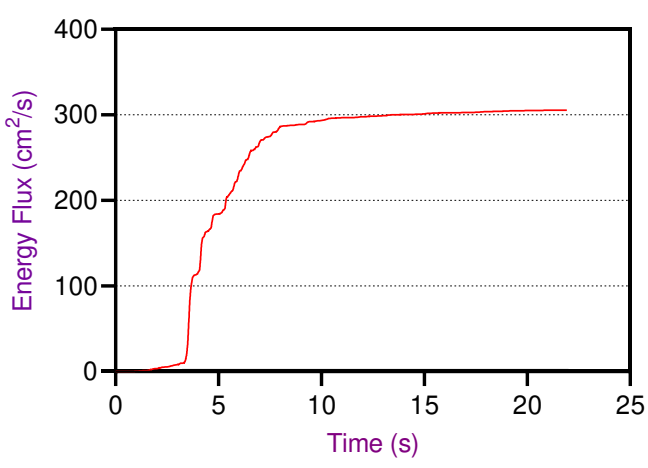

(a)

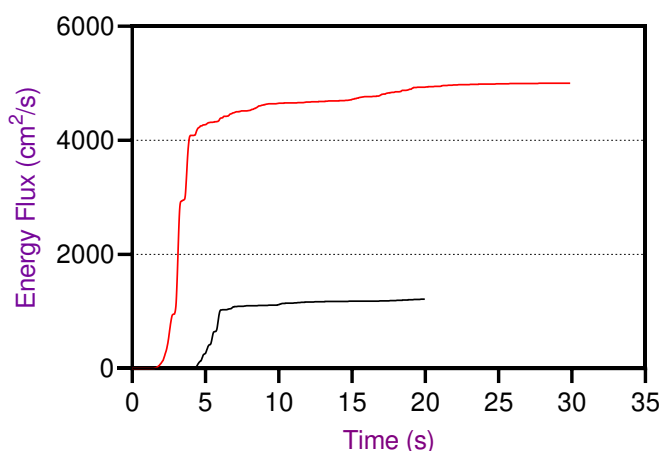

(b)

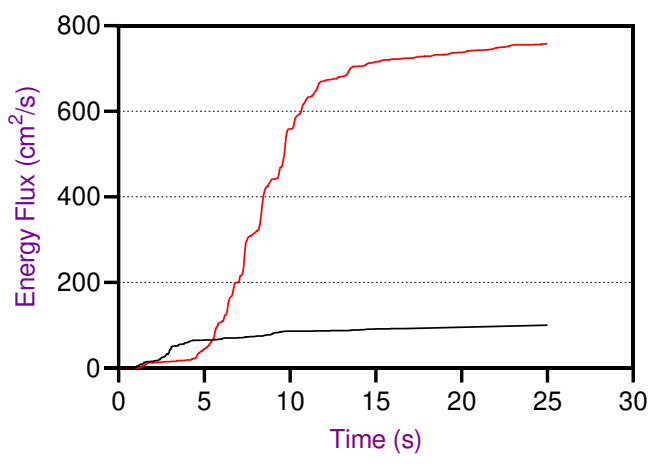

(c)

Mainshock

Aftershock

Fig. 17. Mainshock-aftershock cumulative energy diagram: (a) Friuli (b) Cape Mendocino (c) Mammoth Lakes

The shear wall systems are mainly used in 4-35 story buildings (Megson, 2005). As maintained in section 4.1.1, the three-story model, the value of relative displacement under ground motions is very low (insignificant) also seismic sequences cause no growth in relative and residual displacement. Somehow, this model behaves overdesign under seismic loads and only shows elastic behavior under all three mainshock-aftershocks. 


\section{Conclusions}

This research studied the behavior of two structure models of six and three floors with a shear wall system under three different real mainshock-aftershock seismic sequences. The nonlinear dynamic explicit time-history analysis was used to evaluate the seismic behavior of the models. According to the results, the following conclusions can be drawn:

The nonlinear analysis of the three-story model shows that the shear wall system in short structures significantly increases the lateral stiffness in which the structure behaves completely elastic during seismic sequences. In this case, it can be implied that the effect of seismic sequences is negligible in the seismic design of these kinds of structures.

The ratio of maximum aftershock acceleration to mainshock acceleration is a very important index in the study of the seismic behavior of structures under seismic sequences. In such a way that a structure under mainshock maybe shows residual displacement but this displacement will not increase due to a weak aftershock like Friuli mainshock-aftershock.

Structures with the shear wall system, the total height of the structure has a significant effect on the seismic behavior under mainshock-aftershock. As the two models of three and six floors show completely different seismic behavior.

Unlike the medium height moment-resisting frame structures under seismic sequences, due to the high lateral stiffness of shear walls against the lateral loads, the drift ratio does not grow with the height of the structure.

In this study, the highest growth of residual displacement and drift ratio occurred on the first floor which shows this floor needs special attention in seismic design procedure under seismic sequences.

Seismic sequences increase the residual displacement and maximum relative displacement of structures even more than $50 \%$ and $25 \%$ respectively. For instance, the residual displacement and maximum relative displacement of the six-story model show 55.61\% and 27.97\% of growth respectively under Mammoth Lakes mainshockaftershock. This significant growth should be considered in seismic design codes of procedure.

\section{Declarations}

Ethical statements (The developed method is the original effort of the authors which is not submitted or published elsewhere)

Funding (This research was not funded by any funding bodies)

Conflict of interest/Competing interests (The Authors declare that they have no conflict of interest)

Availability of data and material (Data and material are available)

Code availability (The developed codes are available)

Plant reproducibility (Not applicable)

Clinical trials registration (Not applicable)

Gels and bolts/ Image manipulation (Not applicable)

High-risk content (Not applicable)

Acknowledgment (There is no acknowledgment)

\section{References}

American Concrete Institute (ACI 318-14). (2014). Committee. Building code requirements for structural concrete and commentary. Michigan, USA.

Amadio, C., Fragiacomo, M., \& Rajgelj, S. (2003). The effects of repeated earthquake ground motions on the non-linear response of SDOF systems. Earthquake engineering \& structural dynamics, 32(2), 291-308. Doi: https://doi.org/10.1002/eqe.225

Amiri, S., \& Bojórquez, E. (2019). Residual displacement ratios of structures under mainshock-aftershock sequences. Soil Dynamics and Earthquake Engineering, 121, 179-193. Doi: https://doi.org/10.1016/j.soildyn.2019.03.021

Astaneh-Asl, A. (2002). Seismic behavior and design of composite steel plate shear walls. Structural Steel Educational Council, USA, California; 2002. 
Carreira, D. J., \& Chu, K. H. (1986). Stress-strain relationship for reinforced concrete in tension. ACI Journal, 83, 21-28.

Iranian Code of Practice for Seismic Resistant Design of Buildings (Standard No. 2800). (2015). Building and Housing Research Center. Tehran, Iran.

Dulinska, J. M., \& Murzyn, I. J. (2016). Dynamic behaviour of a concrete building under a mainshock-aftershock seismic sequence with a concrete damage plasticity material model. Geomatics, Natural Hazards and Risk. 7, 25-34. Doi: https://doi.org/10.1080/19475705.2016.1181341

Etabs tutorial. (2010). Design of a building using: ETABS step by step procedure of designing building in ETABS. Etabs Computers and Structures Inc. Berkeley, California, USA.

Hainzl, S., Steacy, D., \& Marsan, S. (2010). Seismicity models based on Coulomb stress calculations. Community Online Resource for Statistical Seismicity Analysis. Doi: https://doi:10.5078/corssa-32035809.

Hatzigeorgiou, G. D., \& Liolios, A. A. (2010). Nonlinear behaviour of RC frames under repeated strong ground motions. Soil dynamics and earthquake engineering. 30(10): 1010-1025. Doi: https://doi.org/10.1016/j.soildyn.2010.04.013

Hatzivassiliou, M. P., \& Hatzigeorgiou, G. D. (2015). Three-dimensional reinforced concrete structures subjected to mainshock-aftershock earthquake sequences. Paper presented at the 8th GRACM International Congress on Computational Mechanics. Volos, Greece.

Hillerborg, A., Modéer, M., \& Petersson, P. E. (1976). Analysis of crack formation and crack growth in concrete by means of fracture mechanics and finite elements. Cement and concrete research. 6(6), 773-781. Doi: https://doi.org/10.1016/0008-8846(76)90007-7.

Hosseini, S. A., Ruiz-Garcia, J., \& Massumi. A. (2019). Seismic response of RC frames under far-field mainshock and near-fault aftershock sequences. Structural Engineering and Mechanics. 72(3): 395-408. Doi: https://doi.org/10.12989/sem.2019.72.2.000

Hsu, L. S., \& Hsu, C. T. (2015). Complete stress-strain behaviour of high-strength concrete under compression. Magazine of concrete research. 46(169): 301-312. Doi: https://doi.org/10.1680/macr.1994.46.169.301

Johnson, S. (2006). Comparison of Nonlinear Finite Element Modeling Tools for Structural Concrete. CEE561 Project. University of Illinois, Illinois, USA.

Khouri, M. F. (2011). Drift Limitations in a Shear Wall Considering a Cracked Section. International Journal of Reliability and Safety of Engineering Systems and Structures. 1(1): 31-38. http://www.aascit.org/journal/archive2?journalId=920\&paperId=474

Kim, B., \& Shin, M. (2017). Main Shock-aftershock sequential analysis on reinforced concrete columns. Paper presented at the 16th World Conference on Earthquake. Santiago, Chile.

Lee, J., \& Fenves, G. L. (1998). Plastic-damage model for cyclic loading of concrete structures. Journal of engineering mechanics. 124(8): 892-900. Doi: https://doi.org/10.1061/(ASCE)07339399(1998)124:8(892).

Lubliner, J., Oliver, J., Oller, S., \& Onate, E. (1989). A plastic-damage model for concrete. International Journal of solids and structures. 25(3), 299-326. Doi: https://doi.org/10.1016/0020-7683(89)90050-4.

Megson, T. H. G. (2005). Structural and stress analysis. Elsevier, Amsterdam, Netherlands, ISBN: 9780080455341

Mostofinejad, D. (2008). Reinforced Concrete Structures. Arkane danesh, Isfahan, Iran, Vol. 7.

Náprstek, J., Horáček, J., Okrouhlík, M., Marvalová, B., Verhulst, F., \& Sawicki, J. T. (2011). Vibration Problems. Paper presented at the 10th International Conference on Vibration Problems (Vol. 139). Springer Science \& Business Media, Netherlands. https://doi.org/10.1007/978-94-007-2069-5

Ōmori, F. (1984). On the after-shocks of earthquakes. Vol. 7. Imperial University, Tokyo, Japan.

Pacific Earthquake Engineering Research Center. (2011). PEER ground motion database. Data available on the: https://ngawest2.berkeley.edu/.

Pirooz, R. M., Habashi, S., \& Massumi, A. (2021). Required time gap between mainshock and aftershock for dynamic analysis of structures. Bulletin of Earthquake Engineering, 19(6), 2643-2670. Doi: https://doi.org/10.1007/s10518-021-01087-z. 
Qu, B., \& Bruneau, M. (2009). Design of steel plate shear walls considering boundary frame moment resisting action. Journal of structural engineering. 135(12): 1511-1521. Doi: https://doi.org/10.1061/(ASCE)ST.1943-541X.0000069.

Ramberg, W., \& Osgood, W. R. (1943). Description of stress-strain curves by three parameters. NASA, USA, Document ID: 19930081614.

Ruiz-García, J., \& Negrete-Manriquez, J. C. (2011). Evaluation of drift demands in existing steel frames under as-recorded far-field and near-fault mainshock-aftershock seismic sequences. Engineering Structures. 33(2), 621-634. https://doi.org/10.1016/j.engstruct.2010.11.021

Ruiz-García, J., Terán-Gilmore, A., \& Díaz. G. (2012). Response of essential facilities under narrow-band mainshock-aftershock seismic sequences. Paper presented at the proceedings of 15th World Conference on Earthquake Engineering. Lisbon, Portugal.

Ruiz-García, J. (2012). Mainshock-aftershock ground motion features and their influence in building's seismic response. Journal of Earthquake Engineering. 16(5), 719-737. Doi: https://doi.org/10.1080/13632469.2012.663154.

Shear Wall Design Manual ACI 318-14. (2016). Computers \& Structures Inc. Berkeley, California, USA.

Dassault Systèmes. (2017). Getting Start with ABAQUS tutorial. ABAQUS Version 6.14., Providence, RI. Waltham, USA.

Tarigan, J., Manggala, J., \& Sitorus, T. (2018). The effect of shear wall location in resisting earthquake. Paper presented at the IOP Conference Series: Materials Science and Engineering. Sumatera Utara, Indonesia.

Thomsen, J. H., \& Wallace, J. W. (2004). Displacement-based design of slender reinforced concrete structural walls-experimental verification. Journal of structural engineering. 130(4), 618-630. Doi: https://doi.org/10.1061/(ASCE)0733-9445(2004)130:4(618)

Wahalathantri, B., Thambiratnam, D., Chan, T., \& Fawzia, S. (2011). A material model for flexural crack simulation in reinforced concrete elements using ABAQUS. The paper presented at Proceedings of the first international conference on engineering, designing and developing the built environment for sustainable wellbeing. Queensland University of Technology, Australia, Queensland.

Wallace, J. W. (1994). New methodology for seismic design of RC shear walls. Journal of Structural Engineering. 120(3), 863-884. Doi: https://doi.org/10.1061/(ASCE)0733-9445(1994)120:3(863)

Zhai, C. H., Wen, W. P., Li, S., Chen, Z., Chang, Z., \& Xie, L. L., (2014). The damage investigation of inelastic SDOF structure under the mainshock-aftershock sequence-type ground motions. Soil Dynamics and Earthquake Engineering. 59, 30-41. Doi: https://doi.org/10.1016/j.soildyn.2014.01.003

Zhao, C., Yu, N., Peng, T., Lippolis, V., Corona, A., \& Mo, Y. L. (2020). Study on the dynamic behavior of isolated AP1000 NIB under mainshock-aftershock sequences. Progress in Nuclear Energy. 119. Doi: https://doi.org/10.1016/j.pnucene.2019.103144

Zhou, J., Bu, G. B., \& Li, K. N. (2012). Calculation methods for inter-story drifts of building structures. Paper presented at the Proceedings of 15th World Conference on Earthquake Engineering. Lisbon, Portugal. 